\title{
Analysis on the Willingness of Peasant Households for Forestland Use Right Transfer in the Background of Collective Forest Tenure Reform: A Case Study in Guangyuan City in Sichuan Province
}

\author{
Minfeng Tang ${ }^{1} \&$ Fang Wang ${ }^{1}$ \\ ${ }^{1}$ School of Economics and Management, Sichuan Agricultural University, Chengdu, China \\ Correspondence: Minfeng Tang, School of Economics and Management, Sichuan Agricultural University, \\ Chengdu, China. Tel: 86-15520735285.E-mail: tangminf@hotmail.com
}

Received: November 19, 2012 Accepted: December 8, 2012 Online Published: December 18, 2012

doi:10.5539/sar.v2n2p76

URL: http://dx.doi.org/10.5539/sar.v2n2p76

\begin{abstract}
The objective of this study is to get a better understanding and accurate information regarding factors affecting the forestland transfer, providing first-hand information, and proposing policy implications. The forestland use transfer is the main content in the collective forest tenure reform in China at present. Individual household, as a basic unit of forest production, should be the major participant in the forestland transfer. Using survey data of 329 rural household in 18 villages of three counties, this paper analyzes influencing factors on rural householders' willingness to partake in forestland use right transfer by employing Binary Logit Regression. Nineteen variables, which were identified as characteristics of householders and households, natural endowment of forestland resources and householders's awareness of forestland policy. Results indicate that householders' awareness of pertinent policies and population of the household demonstrate significantly positive effects, while forestland area owned by individual household shows a markedly negative effect on peasants' willingness to participate in forestland transfer. Some policy implications are discussed in this paper.
\end{abstract}

Keywords: forest tenure reform, willingness analysis, forestland transfer, peasant household, Sichuan

\section{Introduction}

Since the promulgation of A Decision on Accelerating the Forestry on June 2003, a new round of comprehensive reform of collective forest right system has been carried out nationwide(Wang et al., 2007; Xu, 2010). Up to now, the issuance of forest certificates and the allowance of long contract periods on the scale of 30 to 70 years have been accomplished in most provinces, which has laid a solid foundation for the future establishment of forest tenure market (Qiu, Sun, \& Xu, 2007). Collective forest reform boosts forestland area owned by individual peasant household. Meanwhile, it causes fragmentation of forestland management (Wen, 2008). In areas where collective forests have been allocated to individual household, the costs and complexity of managing forests are likely to increase. However, it is the clarified forestry right and decentralization of forest ownership that provide a prerequisite condition for forestland transfer to occur (Kong, 2008), and it has become evitable now and in the future (Zeng \& Nie, 2009). Forestland right transfer refers to use right transfer and contractual right transfer (Kong, 2008), and its essence lies in the transposition and transaction of property right (Zeng et al., 2009).

Researches on forestland transfer mainly are carried out from maco-level and micro-level perspectives. Zhou (2005) suggests that institutions of both information service and forest resources evaluation be established due to the relatively high information cost and spontaneity characterized by forestry right transfer. Some researchers argue that problems such as deviant operation and incomplete legislation are prevalent during the current process of forestland use transfer (Fan, 2006; Li et al., 2010), thus making it necessary to establish and consummate pertinent legislation systems (Zhou, 2005). Some investigations show that land transactions are quite limited to within the same villages (Wen \& Zhang, 2008; Zhang, Lv, \& Nin, 2011), and are often without formal written contracts except oral agreements (Zhang et al., 2011). Through comparing management efficiency of various forestland transfer, Luo, Li and Chen (2010) explores different realization methods of forestland transfer. During the period of "three determinations" (aiming at stabilizing the present ownership structure of hills and forests; allocating hillsides to farmers for their private use; defining the production responsibility system), a lack of property rights clarity, vague ownership position and inflexible mechanisms used to be the main impediments to 
forestland transfer $(\mathrm{Lv}, 2009)$. While since the implementation of collective forestry tenure reform, occurrence of forestland transfer has increased markedly (Wen et al., 2008). Consequently, the separation of ownership, use right and contracting right guarantees the smooth development of forestland transfer (Zhu \& Yin, 2006).

Individual household, as a basic unit of forest production, should be the major participant in the forestland transfer, as their willingness and behaviors have direct impact on the efficiency of forestland transfer $(\mathrm{Ke}, \mathrm{Li}, \&$ Zhao, 2011). Some researchers analyzed influences on the willingness of forestland transfer from peasants' perspective. Though household survey in Mali County, Yunnan Province, Xu, Wen and Wang (2011) found that influences include education background, awareness of forestland transfer policy, household forestland area, forestry income, accessibility to transfer and the extent to which peasants are satisfied with the evaluation results of forest resources value. Some empirical study results have generally confirmed this finding (e.g. Chen, Zhou, Wang, \& Wang, 2009; Xu et al., 2010; Zhang et al., 2011; Tian et al., 2011; Ran et al., 2011). By contrast, Ran and Lv (2010) conclude that characteristics of household heads, area of forestland and farm land have no effects on forestland transfer through adopting Faustman-pressler-ohlin formula. Ke et al. (2011), based on a cost-benefit analysis frame-work, argued that levels of cost and benefit are the pivotal factors for peasants' decision for partaking in forestland transfer. Likewise, Shi and Jia (2002) compared the agent flow of agricultural production in inland Shanxi Province and the coastal Zhejiang Province, and found that the deep-seated cause for farmland transfer is the comparative efficiency of farmland use. The purpose to increase returns from forestland, especially from those forested land, explaines the motivation of forestland acquisition in some peasant households $(\mathrm{Xu}, 2011 ; \mathrm{Li}, 2011)$. As with the improvement of rural insurance condition and increase in returns from non-forest land, the speed of forestland transfer accelated $(\mathrm{Li}, 2011)$. Although forestland provides a weaker function of social security comparing with farm land, it is viewed as farmer's last safety guard for other endeavors in cities or off-farm business (Zeng et al., 2009).

By and large ,the speed and aim of forestland reform implementation are, to a large extent, subject to the overall progress of rural social and economic transition (Jin, 2003), and the main impediment to the acceleration of forestland transfer lies in the social burdens that forestland undertakes (Zeng et al., 2009).

To sum up, current researches on forestland transfer, based on both macro level and micro level, are multi-dimensional. Factors affecting the willingness of forestland transfer can be identified as two broad categories: household characteristics and non-household characteristics, and further, characteristics of household and householder, natural endowment of forest resources and institutional environmental factors. In general, most researches are at the aggregate level and primarily address administrative issues, studies at the household level are far from enough, and research area such as influences on peasants' willingness to participate in forestland transfer needs to be strengthened (Xu et al., 2010). So far, the preliminary collective forest reform has come to its end in Sichuan Province, and complimentary reform is underway. Given this backdrop, forestland use right transfer has become a common pursuit of benefit among peasants $(\mathrm{Li}, 2011)$.

The objective of this paper is to explore factors affecting rural households' willingness to participate in forestland transfer, to provide first-hand information and propose policy implications. By investigating sample peasant households, this paper further analyzes peasants' forestland transfer behaviors and patterns.

The structure of the paper is as follows: the next section describes the methodology and data; then, the empirical results are presented. The paper ends with a discussion and conclusion.

\section{Methods and Data}

\subsection{Study Site}

Located in southwestern China, Sichuan Province has rich forest resources and a significant ecological position functioning as an ecological protective screen at the upper reaches of Yangtze River. Sichuan belongs to the southern collective forest region, where collectively owned forests cover an area of 1046 million ha accounting to $45.9 \%$ of forest area (SFA, 2009). Sichuan is one of the 10 provinces with significant amounts of collective forest ownership. Located in the northern mountainous area of Sichuan Basin, Guangyuan City is at the upper reaches of Jialing River, the junction of Sichuan, Gansu and Shanxi provinces. Statistics of Class II Investigation of forest resources indicate that forestland covers an area of 101 million ha, which accounts to $61.9 \%$ of the total land area in Guangyuan City, ranking 6th in Sichuan Province.

\subsection{Methods}

A month of field survey was conducted from July to August in 2011. The survey selected 18 administrative villages from 9 townships, which were dispersed in 3 counties in Guangyuan City, and 329 rural households were interviewed. To ensure the representation of general situation in Guangyan City, we selected Qingchuan, 
Lizhou and Yuanba as sample counties. Forestry is important in all these counties (townships) selected in terms of both income from forestry and forest coverage. In order to ensure that our results and conclusions are representative of the region, we also took into consideration each county's geographic representativeness, forest resources, level of economic development, and dependence on forestry, based on carefully consulting officials from provincial as well as county (municipality) level governments, forestry bureaus, and scholars who are experts on this subject. Therefore, these counties (townships) were chosen according to the gradient of forest cover and economic development situations from north to south: located in the Northern Guangyuan with forest coverage higher than the average level of the city (Qingchuan); located in the middle of Guangyuan as the political, economic and social center with an average forest coverage of the city (Lizhou); located in the south with a relatively lower forest coverage compared to the city's average level (Yuanba). Villages and households were selected randomly within each county. After a preliminary survey was conducted in Yuanshan Village in Lizhou, a pilot forest tenure reform implementation county, arrangements and contents of questionnaire items were modified to cater to the peasants' reading habits. The questionnaire included four parts: the first part asked about age, education, engagement in farming etc.; the second part was to collect information about characteristics of household such as household size, migrant labors etc.; the third part included questions pertaining to forestland variables such as forestland area, number of parcels and other information about forestland transfer; the last part was to acquire information about householders' awareness of forestland transfer policy, household ownership of forestland certificates, participation in decision making at the General Assembly and willingness to engage in forestland transfer. Distributions of household are shown in Table 1.

Table 1. Sample villages and household distribution

\begin{tabular}{|c|c|c|}
\hline County & township & Sample household \\
\hline & Qianzhuang & 35 \\
\hline \multirow{3}{*}{ Qingchuan } & Yaodu & 35 \\
\hline & Zhuyuan & 34 \\
\hline & Total & 104 \\
\hline \multirow{5}{*}{ Lizhou } & Sandui & 36 \\
\hline & Dashi & 37 \\
\hline & Rongshan & 39 \\
\hline & Total & 112 \\
\hline & Hutiao & 38 \\
\hline \multirow{3}{*}{ Yuanba } & Zhangjia & 38 \\
\hline & Weizi & 37 \\
\hline & Total & 113 \\
\hline Total & & 329 \\
\hline
\end{tabular}

In total, 329 valid responses were collected, with a $91.4 \%$ response rate. Sample villages and households were chosen randomly. Specifically, we chose the villages from the village list of a county and households from the household list of a village. Our initial survey was conducted in June as part of our program monitoring and assessment efforts. As can be seen from Table 1, nine townships were randomly chosen within Qingchuan, Lizhou and Yuanba County. We acquired 104,112 and 113 sample households from Qingchuan, Lizhou and Yuanba, respectively.

\subsection{Statistical Analysis}

To identify factors that may influence householders' willingness to participate in forestland transfer, a discrete variable logit analysis was carried out. The willingness of the participants as to whether they are willing to engage in forestland transfer can be framed as binary-choice models which assume that individuals are faced with a choice between two alternatives (willing or unwilling) and the choice depends on identifiable characteristics. Let $T_{i}$ represent a dichotomous variable that equals 1 if the respondent is willing to engage in forestland transfer and 0 if otherwise. The probability of householders' willingness in participatory forestland 
transfer, $P_{r}\left(T_{i}=1\right)$, is a cumulative density function $F$ evaluated at $X_{i} \beta$, where $X_{i}$ is a vector of explanatory variables and $\beta$ is a vector of unknown parameters. This kind of cumulative density function can be modeled using a logistic probability function, which has the following form:

$$
\begin{gathered}
\left.\mathrm{P}_{\mathrm{r}} \text { (Household heads is willing }\right)=\mathrm{P}_{\mathrm{r}}\left(\mathrm{T}_{\mathrm{i}}=1\right) \\
=\frac{\exp \left(\mathrm{X}_{i} \beta\right)}{1+\exp \left(\mathrm{X}_{i} \beta\right)}=\beta_{0}+\beta_{1} X_{1}+\beta_{2} X_{2}+\ldots \beta_{n} X_{\mathrm{n}}
\end{gathered}
$$

In order to estimate the parameters of the variables influencing householders' willingness to participate in forestland use transfer, a maximum likelihood estimation was used as shown in Equation (1).

\subsubsection{Variables Used in the Model}

Based on existent research results (e.g. Shi et al., 2002; Liao et al., 2010; Zhang et al., 2011; Xu et al., 2011; Tian et al., 2011), 19 variables, which were categorized into 4 categories, were selected, and characteristics of respondents (sample householders) and detailed definitions of these variables are shown in Table 2.

\begin{tabular}{|c|c|}
\hline Variables & Description and measurement \\
\hline AGE & variable indicating the age of the householder \\
\hline EDU & variable indicating years of householder was in school \\
\hline $\mathrm{EF}$ & dummy variable: " 1 " if householder is engaged in farming, "0" otherwise \\
\hline PTT & dummy variable: " 1 " if the householder has ever participate in technical training, " 0 "otherwise \\
\hline $\mathrm{PM}$ & dummy variable: " 1 " if the householder is a party member, " 0 " otherwise \\
\hline $\mathrm{VC}$ & dummy variable: " 1 " if the householder is a village cadre, " 0 " otherwise \\
\hline WFP & $\begin{array}{l}\text { dummy variable: " } 1 \text { " if the householder has ever worked or is presently working in a forestry } \\
\text { department, "0"otherwise }\end{array}$ \\
\hline POP & variable indicating population of the household \\
\hline NAEF & variable indicating the number of adults engaged in farm work \\
\hline AEFL & variable indicating the area of ecological forestland owned by the household \\
\hline PAR & variable indicating the number of parcels of the forestland owned by the household \\
\hline AFL & variable indicating the area of forestland owned by the household \\
\hline TFL & dummy variable: "1" if the type of household forestland is economic forest, "2" otherwise) \\
\hline AGA & dummy variable: " 1 " if the householder has ever attended the General Assembly, " 0 " otherwise \\
\hline INC & dummy variable : " 1 " if the household has a steady income stream, "0"otherwise \\
\hline NMW & variable indicating the number of migrant worker within the household \\
\hline FLUC & dummy variable: " 1 " if the household has received forestland use certificates, " 0 " otherwise \\
\hline PFPM & $\begin{array}{l}\text { dummy variable: " } 1 \text { " if the householder knows about policy of forestry property mortgage, } \\
\text { " } 0 \text { "otherwise }\end{array}$ \\
\hline FLTP & dummy variable: "1" if the householder knows forestland transfer policy,"0" otherwise \\
\hline
\end{tabular}

Table 2. Description and measurement of independent variables

The outcome variable. The outcome variable is householders' willingness to participate in forestland transfer, which is coded with the value 1 to indicate the house headers' favor of participation and zero otherwise.

Independent variables. It is assumed that the factors listed in Table 2 may influence householders toward forestland transfer and thus the factors were included in the model as independent variables.

\subsubsection{Model}

Given the above-mentioned factors influencing farmers' attitudes in favor of forestland transfer, the model to be estimated is 


$$
\begin{aligned}
& { }_{L n}\left[\frac{p_{r}\left(\mathrm{~T}_{i}=1\right)}{1-p_{r}\left(\mathrm{~T}_{i}\right)}\right] \\
& =\mathrm{b}_{0}+\mathrm{b}_{1}(\mathrm{AGE})+\mathrm{b}_{2}(\mathrm{EDU})+\mathrm{b}_{3}(\mathrm{EF})+\mathrm{b}_{4}(\mathrm{PTT})+\mathrm{b}_{5}(\mathrm{PM})+\mathrm{b}_{6}(\mathrm{VC})+\mathrm{b}_{7}(\mathrm{WFP})+\mathrm{b}_{8}(\mathrm{POP}) \\
& +\mathrm{b}_{9}(\mathrm{NAEF})+\mathrm{b}_{10}(\mathrm{AEFL})+\mathrm{b}_{11}(\mathrm{NPFL})+\mathrm{b}_{12}(\mathrm{PAR})+\mathrm{b}_{13}(\mathrm{TFL})+\mathrm{b}_{14}(\mathrm{AGA})+\mathrm{b}_{15}(\mathrm{INC})+\mathrm{b}_{16}(\mathrm{NMW}) \\
& +\mathrm{b}_{17}(\mathrm{FLUC})+\mathrm{b}_{18}(\mathrm{PFPM})+\mathrm{b}_{19}(\mathrm{FLTP})
\end{aligned}
$$

\subsubsection{Test of Hypotheses of the Logistic Regression Model}

Because of the sample size, the test that a coefficient is 0 can be based on the Wald statistic, which has a $\chi^{2}$ distribution. When the variable has a single degree of freedom, the Wald statistic is just the square of the ratio of the coefficient to its standard error. The corresponding $\chi^{2}$ critical values at the $1 \%$ and at the $5 \%$ level of significance will determine a rejection or an acceptance of the null hypothesis.

\section{Results}

\subsection{Characteristics of the Variables Included in the Model}

Table 3 shows characteristics of the 19 independent variables tested. Average age of sample householders was 50 years old, the minimum was 17 and the maximum was 79 . As for education background, an average householder received 6.7-year schooling. Of the respondents, 224 householders were engaged in farming (74.2 per cent); 77 had received technical training ( 23 percent); and village cadres made up $10 \%$ of the sample pool. In term of household size, the population of average household was 4 , the maximum number was 10 , while the minimum was 1 . Average forestland area owned by individual household was $16.3 \mathrm{mu}(\mathrm{Mu}$ is a Chinese unit of measure: 1 $\mathrm{mu}=1 / 15 \mathrm{ha}$.), $4.1 \mathrm{mu}$ per person; and the number of parcels of the forestland owned by individual household was 4 , approximately 1.3 parcels per person. 189 (54.8 per cent) sample households had at least one parcel of ecological forestland.

Table 3. Independent variables

\begin{tabular}{llllllllll}
\hline Variable & Minimum & Max & Mean & St.Err & Variable & Minimum & Max & Mean & St. Err \\
\hline AGE & 17 & 79 & 49.95 & 10.46 & PAR & 1 & 21 & 5.38 & 3 \\
EDU & 0 & 12 & 6.74 & 2.82 & AFL & 0.2 & 275 & 16.28 & 29.73 \\
EF & 0 & 1 & 0.75 & 0.44 & TFL & 1 & 2 & 1.25 & 0.46 \\
PTT & 0 & 1 & 0.34 & 0.47 & AGA & 0 & 1 & 0.18 & 0.38 \\
PM & 0 & 1 & 0.14 & 0.35 & INC & 0 & 1 & 0.12 & 1.01 \\
VC & 0 & 1 & 0.1 & 0.3 & NMW & 0 & 2 & 0.41 & 0.50 \\
WFP & 0 & 1 & 0.01 & 0.11 & FLUC & 0 & 1 & 0.46 & 0.36 \\
POP & 1 & 11 & 3.97 & 1.44 & PFPM & 0 & 1 & 0.35 & 0.48 \\
NAEF & 0 & 5 & 1.71 & 0.98 & FLTP & 0 & 1 & 0.34 & 0.48 \\
AEFL & 0 & 275 & 8.13 & 26.90 & & & & & \\
\hline
\end{tabular}

\subsection{Parameter Estimates of the Logistic Regression Model}

Table 4 shows parameter estimates of the logistic regression model. To avoid multiple conjugate linear of input factors, correlation of explanatory variables was analyzed by using SPSS 16.0. It turns out that, some variables are perfectly correlated and cannot enter the regressions simultaneously e.g. years of education is perfectly correlated with whether the householder is engaged in farming, that whether the householder is a party member is perfectly correlated with both education and that whether the householder is a village cadre; household size is perfectly correlated with number of migrant workers within the household etc.

The results of regression model reveal that householders' awareness of forestland transfer policy and the area of forestland owned by a household have positive effects, while that the number of persons living in a house has a negative effect on people's willingness to sell or acquire forestland. 
Table 4. Results of Logit Model

\begin{tabular}{lllllll}
\hline Explanatory variables & B & S. E. & Wald & df & Sig. & Exp (B) \\
\hline AGE & 0.031 & 0.049 & 0.421 & 1 & 0.516 & 1.032 \\
EDU & 0.523 & 0.202 & 6.691 & 1 & 0.210 & 1.688 \\
EF & -1.537 & 1.545 & 0.990 & 1 & 0.320 & 0.215 \\
PTT & -1.611 & 1.088 & 2.191 & 1 & 0.139 & 0.200 \\
PM & -1.776 & 1.382 & 1.651 & 1 & 0.199 & 0.169 \\
VC & -0.329 & 1.454 & 0.051 & 1 & 0.821 & 0.719 \\
WFP & -0.851 & 4.288 & 0.039 & 1 & 0.843 & 0.427 \\
POP* & -0.509 & 0.286 & 3.172 & 1 & 0.035 & 0.601 \\
NAEF & 0.239 & 0.620 & 0.149 & 1 & 0.700 & 1.270 \\
AEFL & 0.861 & 1.316 & 0.428 & 1 & 0.513 & 2.365 \\
PAR & 0.084 & 0.516 & 0.026 & 1 & 0.871 & 1.087 \\
AFL** & 0.018 & 0.007 & 7.319 & 1 & 0.007 & 1.018 \\
TFL & -0.105 & 0.139 & 0.568 & 1 & 0.451 & .901 \\
AGA & 0.025 & 0.016 & 2.499 & 1 & 0.114 & 1.025 \\
INC & -0.473 & 1.061 & 0.199 & 1 & 0.656 & 0.623 \\
NMW & -1.657 & 1.234 & 1.802 & 1 & 0.179 & 0.191 \\
FLUC & 0.693 & 0.409 & 2.866 & 1 & 0.090 & 2.000 \\
PFPM & 1.099 & 0.983 & 1.250 & 1 & 0.264 & 3.000 \\
FLTP*** & 7.614 & 0.886 & 73.939 & 1 & 0.002 & 2026.960 \\
Constant & -3.048 & 1.161 & 6.898 & 1 & 0.009 & 0.047 \\
\hline
\end{tabular}

$*$ significant level of $0.10 ; * *$ significant level of $0.05 ; * *$ significant level of 0.01 .

\subsection{Logit Model Test Result}

As Table 5 shows: chi-square value is 5.181 , and the value of $p$ is 0.002 , less than 0.05 , which manifests that the precision of the model is at a significant level. That is to say, each regression coefficient value of the correspondent independent variable is not zero simultaneously and indicate a significant correlation between these independent variables and the dependent variable. Specifically, statistic value of -2 Log likelihood is 76.795, while the Cox and Snell R Square value is 0.345 and the Nagelkerke R Square is 0.567 , which demonstrates a fineness of fit with a prediction correctness rate up to $52 \%$.

Table 5. Logit model test results

\begin{tabular}{|c|c|c|c|c|c|c|}
\hline \multicolumn{3}{|c|}{ Hosmer and Lemeshow Test } & \multicolumn{3}{|c|}{ Model Summary } & \multirow{2}{*}{$\begin{array}{l}\text { Accuracy } \\
\text { Percentage } \\
\text { correct }\end{array}$} \\
\hline Chi-square & df & sig. & $\begin{array}{l}-2 \log \\
\text { likelihood }\end{array}$ & $\begin{array}{l}\text { Cox \& Snell } \\
\text { R Square }\end{array}$ & $\begin{array}{l}\text { Nagelkerke } \\
\text { R Square }\end{array}$ & \\
\hline 5.181 & 8 & 0.002 & 76.795 & 0.345 & 0.567 & $66.9 \%$ \\
\hline
\end{tabular}

\section{Discussion and Conclusion}

Statistics show that householders' awareness of forestland transfer policy has a significant effect on people's willingness to sell or acquire forestland. And that also accounts for the rare occurrence of land use right transfer.But for those who acquire more knowledge about pertinent policy express stronger will and are more likely to engage in forestland transfer. Survey results show that only $34.3 \%$ (householders) respondents alleged that they had a comprehensive understanding of the provision. Results from field survey also indicate people's 
lack of awareness of its provision, particularly with regard to which stipulations are included in circulation contracts, how to divide returns from managed forestland and whether forestry property mortgage is approved by law. It may be caused by frequently changing policy and not enough policy dissemination work has been done at the grass root level.However, Deininger et al. (2007) found that although both local governments and village leaders undertook extensive dissemination of information about the Law, only $21 \%$ of village leaders were aware that land transfers were permitted. Therefore, further research on how to raise peasants' awareness to the forestland transfer provision is needed.

Likewise, according to statistic results, forestland area owned by individual household exert a significant effect on farmers' decision to participate in forestland transaction activities. Households with larger area of forestland show more preference to obtain or sell forestland. Although great expenditure and intensive labor on road construction and land clearing are demanded in the initial afforestation periods, little efforts are needed after forests become mature. Since the implementation of forest tenure reform, many tracks of the collectively owned forestland have been divided equally according to the number of households or adults of the village and then allotted to individual families via a simple draw of lottery (Liu \& Yao, 2011). Based on fieldwork results, average forestland area per sample household is $16.3(\mathrm{mu})$, well below the theoretically scale-economic standard (Yang, 2010), for forestland management is characterized by scale-economy. However, it is not clear that full-scale commercialization would be the most effective remedy for this problem; tenure reform is likely a necessary but not sufficient condition for improving the forestry sector's economic efficiency. Due to cumulative effects of forestland management, households with large area of forestland are more willing to obtain extra forestland by paying certain amount of fees, while households with small size tend to sell their forestland to others.

As can be seen from aforementioned statement, the number of people living in a household has a negative effect on people's willingness to take part in forestland transfer activities. That is to say, forestland transfer is more likely to happen in households whose population is relatively large, and vice versa. However, this conclusion contradicts with some current research results (e.g. Kong et al., 2011). It is found in the field survey that united families (two or more families living together) are generally reluctant to participate in forestland transaction. Although returns from forestland management is low, forestland is cherished as family inheritance precluding any change to its existent condition. By contrast, households with small number of members are more willing to sell these parcels of forestland because of difficulty in supervision of illegal logging due to lack of labor force within the family.

While this study provides detailed information on willingness on rural householders' forestland use rights transfer and represents much of the collective forest area in Sichuan Province, we should be cautious to extend the results to the other regions. More investigation is needed to understand land transactions and the impact on forestland management.

In a broad sense, the collective forest tenure reform has accomplished one of the stated objectives by the central government:to clarify property rights among rural small holders, thus providing a strong framework for further forestry development. The growing trend of forestland use right circulation is not only a rational choice made by farmers in a market economy, but also caters to the demand of modern forestry development, with the ultimate goal of rational allocation of forestry resources, as well as increasing rural income.

Analysis of the factors that may influence farmers' willingness to participate in forestland transfer yields the following policy implications and recommendations. Firstly, the pace of implementary reform should be accelerated, with focus on relaxing the harvest restrictions, standardizing circulation procedures and further opening wood market. Only when external environment is ameliorated and information asymmetry is greatly reduced will forestland transfer increase significantly. For example, more measues should be taken to improve flexibility of logging quota arrangements. Current logging regulations stipulate that the quota must be used within one year of allocation.this is not the most economically efficient way. Secondly, more attention should be given to those peasants who are in a less favorable trading position while encouraging more forestland to be transferred. A "seller's market" for forestland will increase property values and create greater disparity in ownership, with wealthier individual households expanding their ownership. The poor are more likely to transfer their forestland due to its increasing value, but they also need appropriate livelihood once they have transferred their land rights. Therefore, the distribution of property to the rural smallholders must be carefully managed. Thirdly, in developing a more complete framework of laws and regulations, policy, and implementation plans and measures, the opinions of local people and specialists should be heard and their experiences respected. Becasue the "grassroots" approach also has great potential for corruption and opacity of implementation. Local governments must work cooperatively with peasants to adopt effective strategies and to ensure transparency and 
equitable opportunity.

\section{Acknowledgements}

The Journal's editors and two reviewers provided valuable comments on earlier drafts of the paper, and their help is greatly appreciated. Any remaining errors are the authors' responsibility.

\section{References}

Chen, K., Zhou, R. W., Wang, C. P., \& Wang, J. (2009). Research on factors influencing on peasant households' willingness of forestland transfer after collective forest tenure reform. Issues of Forestry Economics, 29(6), 493-498 (in Chinese).

Deininger, K., Jin, S., \& Rozelle, S. (2007). Dynamics of legal change in a decentralized setting: Evidence from China's Rural Land Contracting Law. World Bank Policy Research Working Paper No. 3981.

Fan, X. B. (2006). Discussion on forestland transfer and circulation. Forestry Resources Manangement, 4, 29-32 (in Chinese).

Jin, X. M. (2003). Comments on farmland institutional research since China's Reform and Opening Up. Chinese Rural Economy, 2, 14-24 (in Chinese).

Kong, F. B., \& Liao, W. M. (2011). Behavior analysis of household forestland transfer based on structural differences of income: a case study in Jiangxi Province.Chinese Rural Economy, 8, 89-95(in Chinese).

Kong, F. B., \& Du, L. (2008). Research on regulating the circulation of collective forest property rights. Issues of Forestry Economics, 5, 377-384 (in Chinese).

Ke, S. F., Li, Z., \& Zhao, T. Z. (2011). The cost-benefit analysis and strategies on forestland usufruct transfer among households. Issues in Agriculture Economy, 5, 71-77 (in Chinese).

Liao, W. M., Peng, T. Z., \& Cao, J. H. (2010). Analysis on affecting the households' deciding behavipr in forestland transaction-a case study in Jiangxi Province. Forestry Economics, 5, 39-43(in Chinese).

Li, J. P., Li, J. J., Luo, P. Z., Zhang, H. W., Fen, X. L., \& Tang, X. (2010). Analysis of the results and existing problems of collective forest region in Hunan Province. Journals of Central South University of Forestry and Technology, 30, 89-94 (in Chinese).

Li, Y. (2011). Analysis on forestry peasants' willingness of forestland transfer in the background of collective forest tenure reform. Study and Exploration, 3, 168-170 (in Chinese).

Liu, D. C. (2001). A Preliminary Study of China's Forest Tenure Reform (Working Reform for the World Bank). State Forestry Administration, Beijing, China.

Lv, X. X. (2009). Deepening system reform of collective ownership of forests and speeding up the forestland circulation. Issues of Forestry economics, 29, 81-84 (in Chinese).

Luo, P. Z., Li, J. P., \& Chen, Y. H. (2010). The models ,motives and route choice of forestland circulation and transfer in collective forestry region-based on the case of one county in Hunan Province. Scientia silvae Sinica, 46(9), 158-163 (in Chinese).

Qiu, J., Sun, Y., Li, L., \& Xu, J. T. (2007). Impact of tenure reform on forest management model: a case of Fujian Province. Forestry Economics, 23-27 (in Chinese).

Ran, L. R., \& Lv, J. (2011). Analysis on the desire of the peasant households for forest land management right circulation after collective forest ownership system reform-take 409 peasant households in Liaoning Province as an example. Forestry Resources management, 2, 15-20 (in Chinese).

Shi, Q. H., \& Jia, S. H. (2002). Comarison of trend flow of farmland productive factors and causes in rural households. Management World, 2, 71-92 (in Chinese).

SFA (State Forestry Administration). (2009). Collective Forest Tenure Reform Report. State Forestry Administration, Beijing (in Chinese).

Tian, S. J., \& Zhuo, Y. L. (2011). Empirical analysis factors affecting behavior of farmers' forestland circulation-based on Liaoning Province. Issues of Forestry Economics, 2, 127-130 (inChinese).

Wang, G. Y., Innes, J. L., Lei, J. F., Dai, S. Y., \& Wu, S. W. (2007). China's forestry reforms. Science, 318, 1556-1557. http://dx.doi.org/10.1126/science.1147247

Wen, C. Y., \& Zhang, L. (2008). Analysis on peasant household behaviors of forestland transfer in the background of collective forest tenure reform. Forestry Economics, 11, 9-11 (in Chinese). 
Xu, D. D., Wen, B., \& Wang, J. (2011). Analysis on the will of forestland transfer and the affecting factors-based on the study in Malipo County in Yunnan Province. China Forestry Economy, 4, 33-36 (in Chinese).

Xu, X. Y., Shi, D. J., Yang, S. K., \& Li, C. Z. (2010). Analysis on forestland transferring and the affecting factors: a case study in Lin'an and Anji County in Zhejiang Province. Scientia silvae Sinica, 46(9), 150-157 (in Chinese).

$\mathrm{Xu}$, J. T. (2010). Collective forest tenure reform in China: what has been achieved so far? In: World Bank Conference on Land Governance. World Bank, Washington, DC.

Zeng, H. F., \& Nie, Y. (2009). Forest land transactions: necessity and measures to control market weakness. Journal of Beijin Forestry University (social science), 8(3), 120-125 (in Chinese).

Zhang, W. J., Lv, J., \& Nin, J. P. (2011). The Factors That Affect the Forest Land Circulation of Farming Households under the Collective Forest Tenure Reform. Journal of Shenyang Agricultural University (social science), 18-26 (in Chinese).

Zhu, H. B., \& Yin, S. H. (2006). To pliot the mechanism of forest land circulation in China. Issues of Forestry Economics, 26(6), 539-542 (in Chinese). 